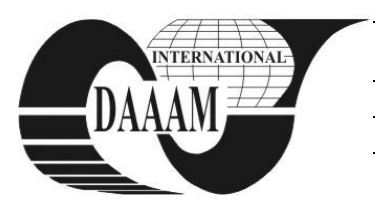

Annals of DAAAM for 2012 \& Proceedings of the 23rd International DAAAM Symposium, Volume 23, No.1, ISSN 2304-1382 ISBN 978-3-901509-91-9, CDROM version, Ed. B. Katalinic, Published by DAAAM International, Vienna, Austria, EU, 2012 Make Harmony between Technology and Nature, and Your Mind will Fly Free as a Bird Annals \& Proceedings of DAAAM International 2012

\title{
MODERNIZATION OF COMMUNICATION INTERFACE BETWEEN MOBILE ROBOT ROBOTINO AND MATLAB SOFTWARE
}

\author{
BREIDO, I[osif] V[ulfovich]; MARKVARDT, R[oman] V[ladimirovich] \& ZARNITCIN, A[lexandr]
}

\begin{abstract}
This article is dedicated to proposals of Karaganda state technical University (Kazakhstan) within the bounds of "Synergy" International education project. The main point of these proposals is use of mobile robot Robotino and Matlab software for the arrangement of remote education. It's supposed to use these playing principles for "Synergy" project participant-universities' students education arrangement. For realization of these porposals modernization of communication protocol is accomplishing.
\end{abstract}

Keywords: List 4-8 keywords (9 pt, italic). Keywords have to be suitable, clear, concise, adequate and accurate

\section{INTRODUCTION}

Matlab software packages are widely used in science, engineering and training.

One promising application of the Matlab software is the preparation experts in the field of mechatronics, and, in particular, the study of mobile robots.

One of these robots is Robotino, produced by FESTO concern.

\section{INFORMATION}

Robotino is an autonomous mobile robot, equipped with wheels that can move in any direction. This wheels are called «omni wheel». The robot moves by three DC motors. The axes of these engines are at an angle of 120 degrees relative to each other.
This makes Robotino possible to turn around its axe. Proceeding from the fact that the robot is made primarily for educational purposes only, you can disable parts of it, and examine and consider them separately.

Here are some robot subsystems Robotino, in addition to the robot's body: power supply subsystem, movement subsystem, odometry subsystem, I / O subsystem, Wi-Fi connection subsystem, on-board computer, different types of sensors.In order to educate the students we have upgraded the communication interface between the robot and the Matlab software.

The need to upgrade due to the fact that access to the existing user interface is closed, which reduces the possibility of modeling and programming movement trajectories of the robot, the study of various structures of governance and regulatory laws.

As an example, Fig. 1 shows one of the options implemented by the interface. It represents an analogue of the program in a Matlab software. There is a system, which employs a feedback control ensures the robot at a meeting in the way of any obstacles. The algorithm of this software analog in the form of a block - scheme is shown in Fig.2.

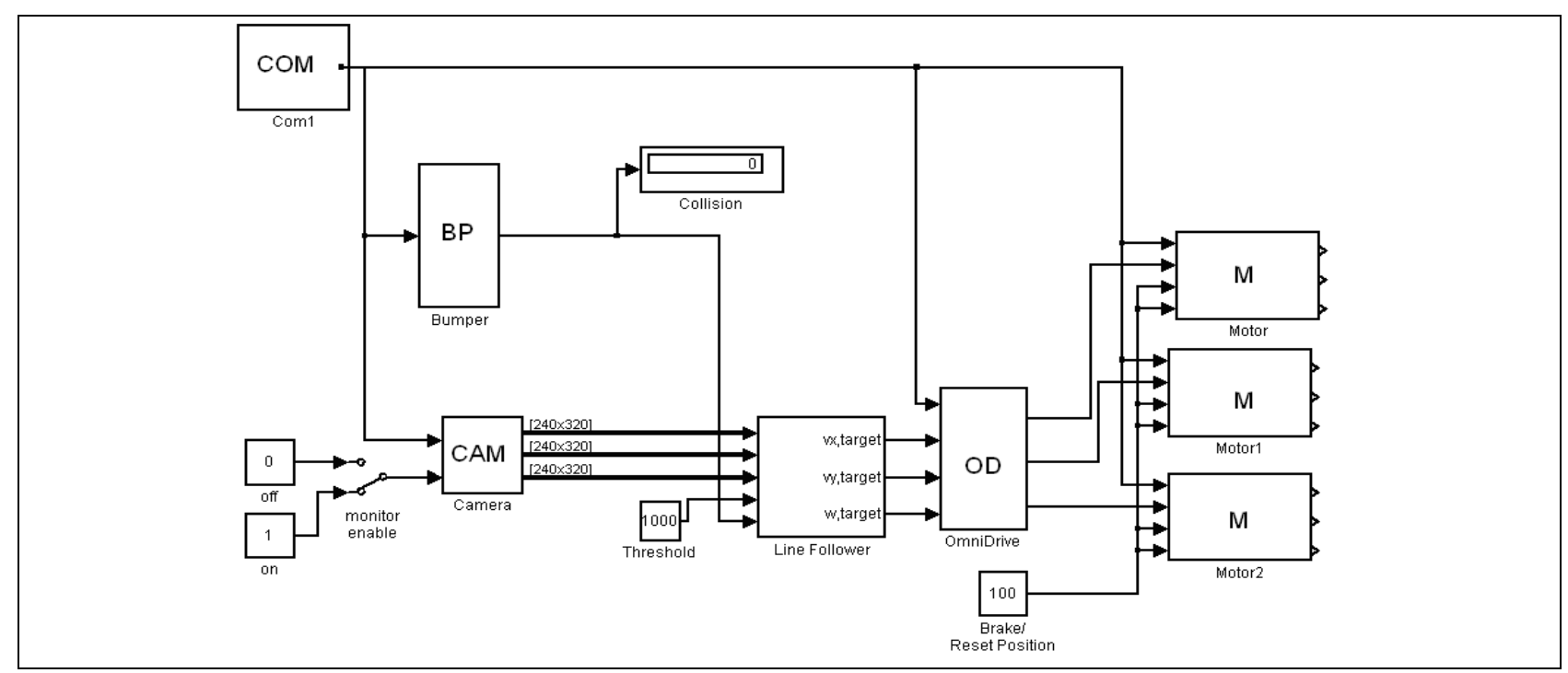

Fig. 1. Software analogue in Matlab system 


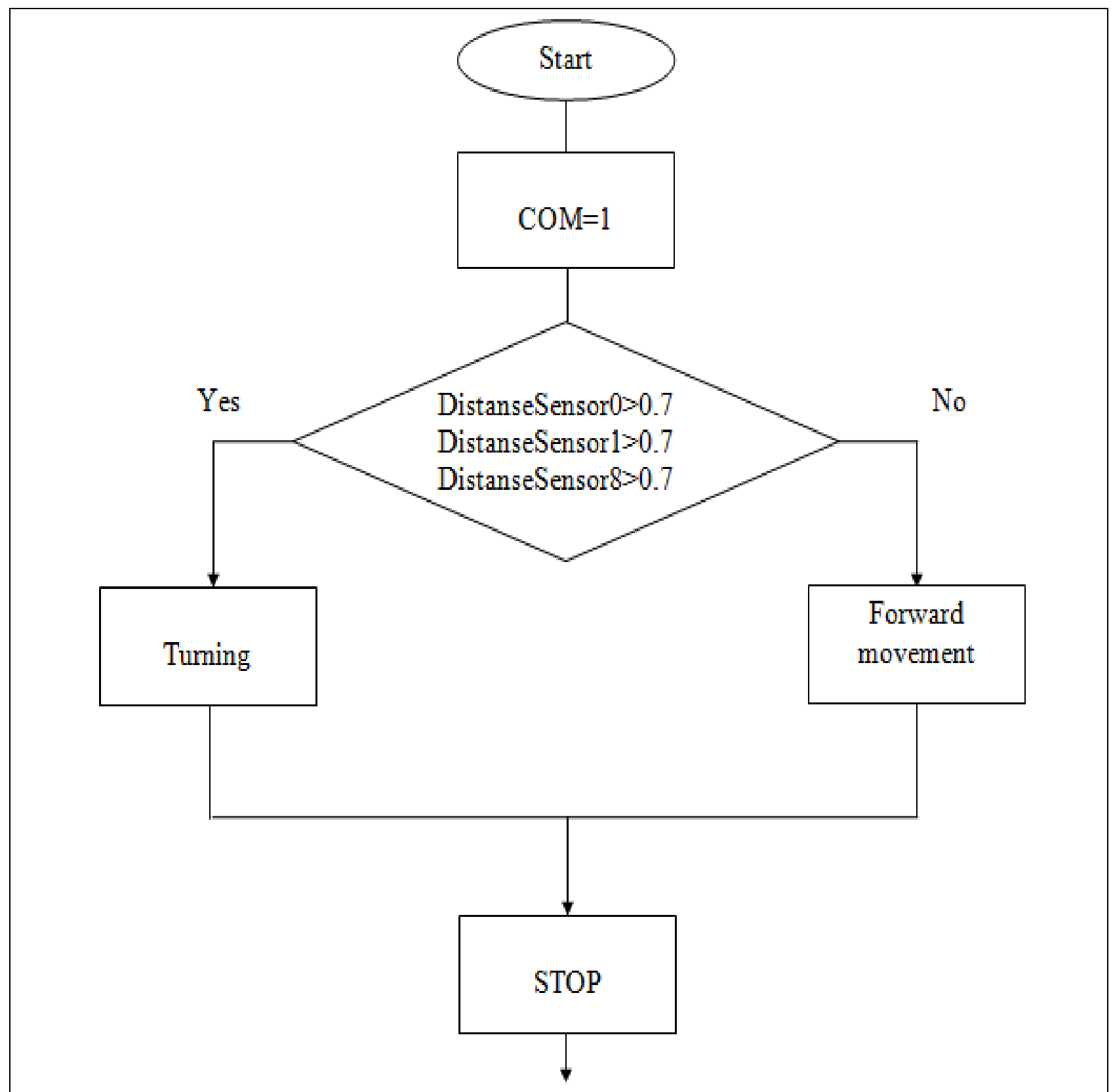

Fig. 2. Block diagram of the feedback algorithm

If the robot moves along the $\mathrm{x}$-axis, it will be used analog sensors DistanseSensor0, DistanseSensor1, DistanseSensor8.

The signal from these sensors is compared to blocks RelationalOperator, which give a signal of logical 1, if the values of the signals exceed $0.7 \mathrm{~V}$.

Subroutine that is responsible for turning the robot is activated as long as the signal from the sensor is below $0.7 \mathrm{~V}$.

The second example of the developed interface is transmission of information in the form of images from the webcam that is installed directly on the robot.

Program analog circuit realizing the transfer of the image shown in Figure 3.

The signal that is transmitted from the webcam is translated into movement of the control signal by using a block LineFollower. It is transmitted by three stepper motor through a block of Omnidrive. Fig. 4 shows a photo directly transmitted from the webcam.

Any scheme of the robot, assembled in Simulink (part of Matlab), must contain Com block. In this block is given an IP address of the robot. Using the same unit wireless transmission of information on the $\mathrm{Wi}-\mathrm{Fi}$ is implemented.

This examples clearly help students learn programming techniques and modeling of the trajectories and motion parameters. They also can learn a principles of the calculation of regulators and other useful applications in the Matlab. When students study mobile robots they can check results of simulation experiment directly with the real object of control .

The developed control system can be used during the laboratory network in the international educational 


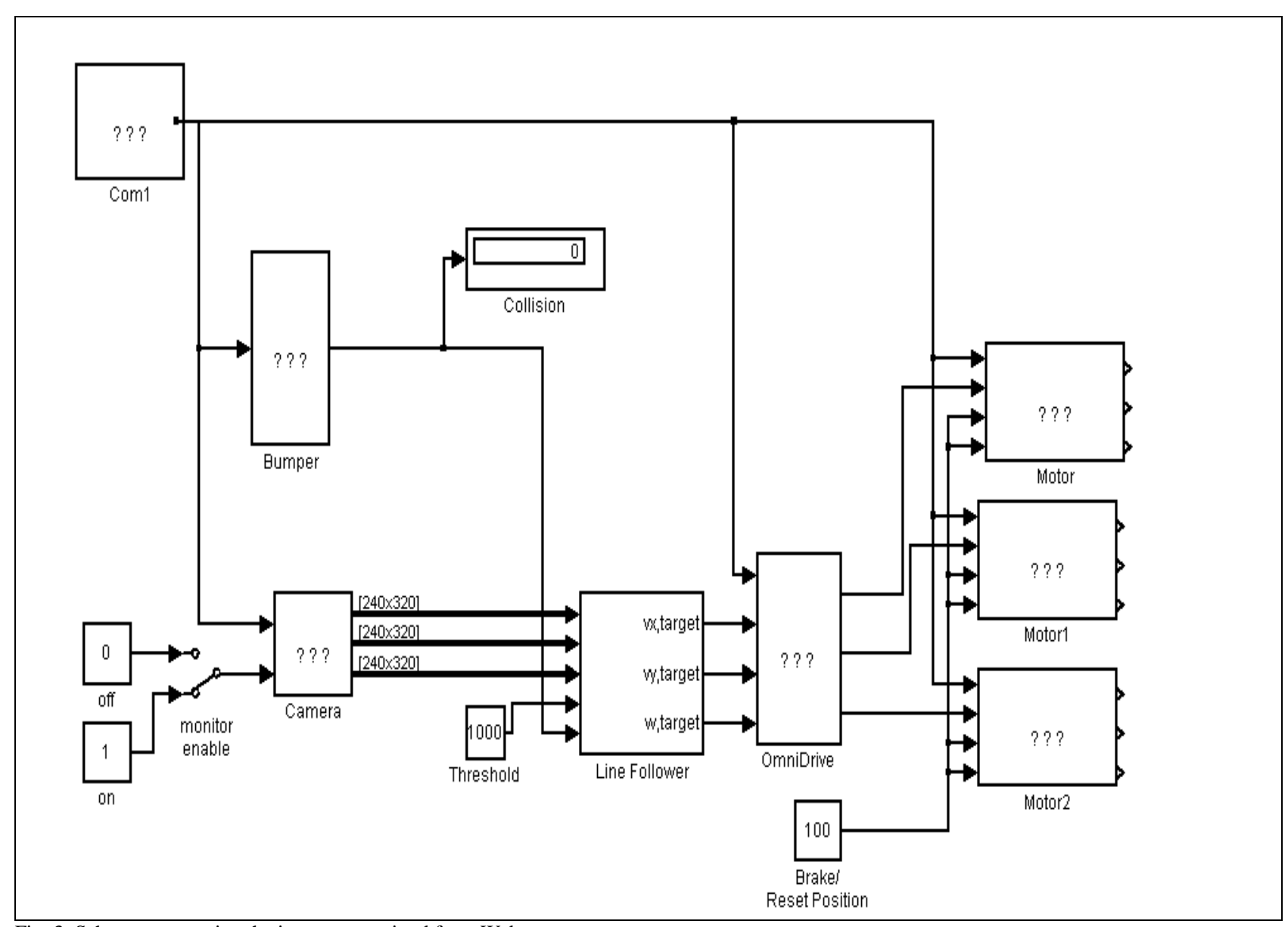

Fig. 3. Scheme, processing the image transmitted from Webcam

project "Synergy". Within the bounds of this project integrated mechatronics training laboratory was created at Karaganda State Technical University (KSTU) based on training equipment of FESTO concern.

At the preliminary stage participants study developed software examples of the interface between Robotino and Matlab software, first presented KSTU for other project participants. Then, each team receives a set of given movement trajectories for Robotino and develops its programs cover a distance.

Debugging a program is possible either in the Matlab, or in the real object. If the university has Robotino, a developed programs are tested on it. In the absence of a mobile robot, working out the programs carried out in the off-line mode with Robotino of other project participants.

In execution of laboratory work on the final assessment affects accuracy and speed of distance passing. Time starts running with turning on of start lamp. The camera mounted on Robotino perceives this signal. And with accordance of control algorithm robot starts the movement.

The tracing of distance passing accuracy realized by check points mounted along the whole distance. Check points are gates with a pair of oscillator and photo receiver. With a breaking of signal on a photo receiver hardware will detect passing of Robotino through the check point. Thus the accuracy of distance passing will be controlled.

Control system is realized on a base of MITSUBISHI Electric programmable logic controller ALPHA2 (ALPHA XL). Optical sensors and start button is connected to inputs of PLC, and start lamp is connected to outputs of PLC.

The structure of control system algorithm could be realized in that way: start realized by giving of start signal by a remote laboratory engineer. At that PLC turns on the start lamp and turns on a timer. As a passing of the distance Robotino must follow the given trajectory passing through the check points.

With the passing of finish line the distance time is fixed. With that if PLC detects passing through all of the check points then elapsed time will be registered given out to a front panel of PLC.

In carrying out laboratory work can be used management of on-line mode. It means that each of participators can watch trend of competitions via webcamera mounted on robot. In this mode device control remains. But the quality of Internet connection could affect on stability of video. Therefore, the most rational and viable option is the organization of laboratory work in the off-line mode, followed by sending videos and results of control by PLC system to all participants in the classes. 


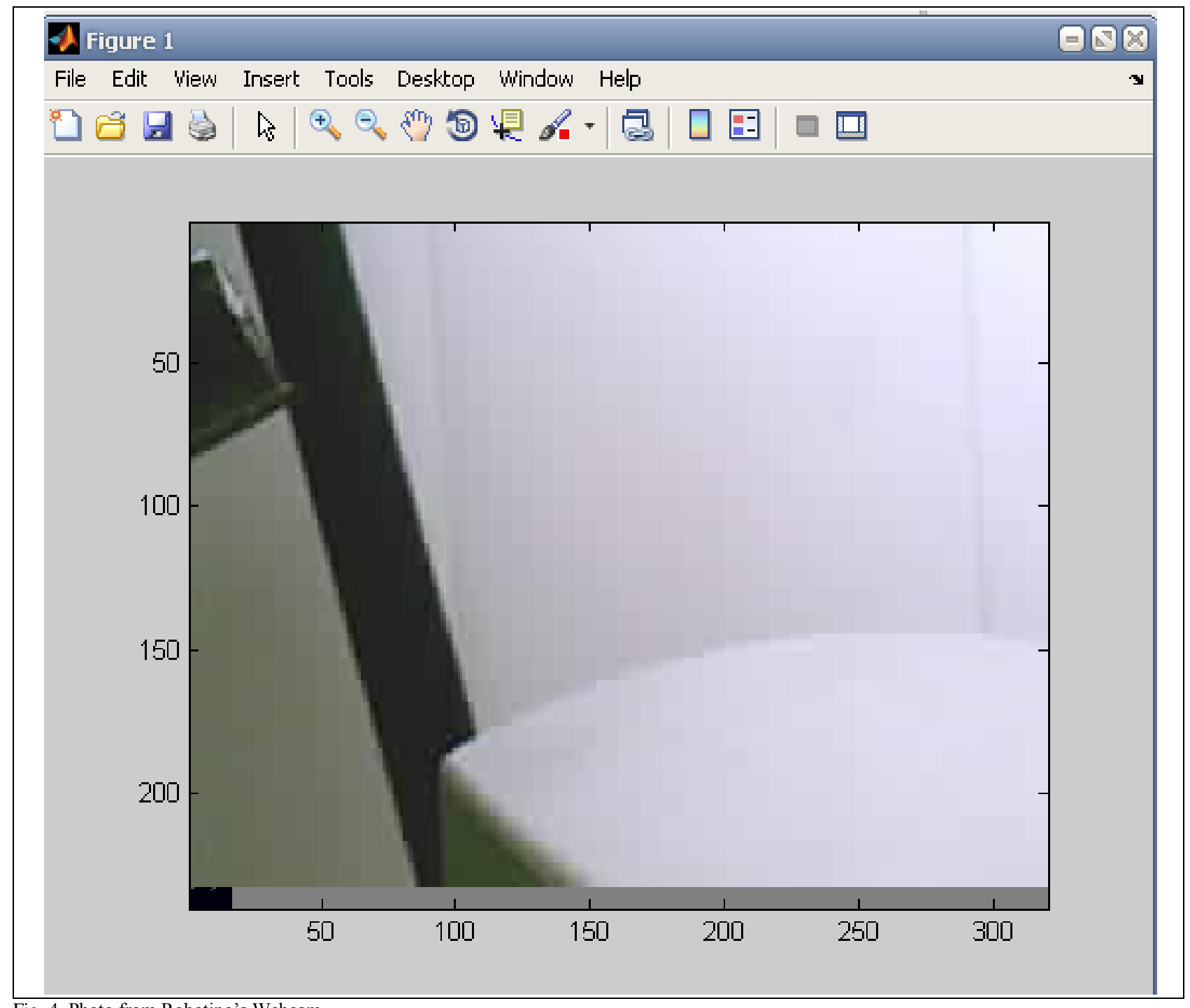

Fig. 4. Photo from Robotino's Webcam

\section{CONCLUSION}

The proposed learning method using Matlab is highly effective because it contains elements of debugging and optimization of algorithms and control laws, including using the principles of fuzzy logic. As a result, the system allows you to maximize the hardware capabilities of robotic system Robotino and computational capabilities of the Matlab software in teaching students and undergraduates in the direction of "Automation and Robotics"

\section{ACKNOWLEDGEMENTS}

The authors of this paper express the profound recognition of all the partners in the international educational project Synergy. For their active part in the discussion of this idea.

In addition, we thank Festo concern for their continued support and development of robotic systems Robotnik, which was a main object of this work.

\section{REFERENCES}

[1] Breido, J.; Markvardt, R. \& Satenov, S. (2009). Use of educational technology through training of students of technical specialties, Proceedings of the International scientific-methodical conference "Modern Education: Challenges and Prospects in the transition to a new concept of education", Bokov, L. (Ed.), p 4849, ISBN 9965-04-441-4, KSTU, 2008-04, KSTU publishing, Karaganda

[2] Breido, J.; Markvardt, R. \& Satenov, S. (2009). Development of remote education technology, Proceedings of the International scientific-practical conference "Use of distance learning technologies in higher education", Tuymebaev, J. (Ed.), p 186189, ISBN 9965-04-441-4, KSTU, 2008-04, KSTU publishing, Karaganda

[3] Feshin, B.; Kotov, E.; Markvardt, R. \& Sharyy, S. (2009). Mechatronic complex Robotino in Synergy project. Automation and Computer Science, No. 1-2, (2009) 45-50, ISSN 1560-7305

[4] Markvardt, R. \& Satenov, S. (2008). Application of remote sensing methods in the preparation of engineering personnel, International scientific-methodical conference "The scientific community of ethnic Germans in Central Asia and Russia: Current Status and Prospects", pp. 219-227, ISBN 978-601-204016-6, KEU, 2008-04, Arko, Karaganda

[5] http://www.mpei-festo.ru/partners.html (2012) - MEI-Festo Institute, Accessed on: 2012-03-15

[6] Murdalova, E.; Parshyna, G. \& Smagulova, K. (2009). Development of electronic learning tools for automation of technological processes and production. Automation and Computer Science, No. 1-2, (2009) 68-70, ISSN 1560-7305 